\title{
Vivências e significados da Consulta do Enfermeiro em puericultura: análise à luz de Wanda Horta*
}

Lived Experiences and meanings of the Nurse Consultation in Childcare: analysis in the light of Wanda Horta

Experiencias y significados de la Consulta de enfermeras en cuidado infantil: análisis a la luz de Wanda Horta

\section{Cheila Karei Siega', Edlamar Kátia Adamy', Beatriz Rosana Gonçalves de Oliveira Toso ${ }^{\mathrm{III}}$ Denise Antunes de Azambuja Zocche ${ }^{\mathrm{IV}}$, Elisangela Argenta Zanatta ${ }^{\mathrm{V}}$}

\begin{abstract}
Resumo: Objetivos: analisar os significados atribuídos à Consulta do Enfermeiro em puericultura na Atenção Primária à Saúde à luz da Teoria de Wanda Horta e conhecer as vivências desses profissionais acerca da sua operacionalização. Método: pesquisa-ação com 15 enfermeiros atuantes na Atenção Primária à Saúde. Dados coletados por entrevistas semiestruturadas, organizados, considerando a análise de conteúdo e interpretados à luz da Teoria. Resultados: revelaram-se três categorias: história pregressa e atual da criança e sua família; Etapas para a implementação do cuidado sistematizado e Dificuldades para realizar a Consulta do Enfermeiro em puericultura na Atenção Primária à Saúde. Conclusão: em suas vivências os enfermeiros relatam dificuldades que culminam na fragmentação da Consulta, entretanto, a significam como oportunidade para conhecer a criança e família na sua integralidade. A operacionalização sistemática da Consulta em puericultura proporciona o empoderamento profissional, qualificação da assistência e fortalecimento da profissão como ciência do cuidado.
\end{abstract}

\footnotetext{
* Extraído da Dissertação "Desenvolvimento de técnica instrumental: construção e validação de um subconjunto terminológico da CIPE ${ }^{\circledR}$ para a Consulta de Enfermagem em puericultura”, Programa de Pós-Graduação em Enfermagem, Universidade do Estado de Santa Catarina (UDESC), 2019.

I Enfermeira. Mestre em Enfermagem. Universidade do Estado de Santa Catarina. Chapecó, Santa Catarina, Brasil. E-mail: cheilasiega@gmail.com; ORCID: https://orcid.org/0000-0001-9272-2526

II Enfermeira. Doutora em Enfermagem. Universidade do Estado de Santa Catarina. Chapecó, Santa Catarina, Brasil. E-mail: edlamar.adamy@udesc.br; ORCID: https://orcid.org/0000-0002-8490-0334

III Enfermeira. Doutora em Enfermagem. Universidade Estadual do Oeste do Paraná. Cascavel, Paraná, Brasil. E-mail: lb.toso@gmail.com; ORCID: https://orcid.org/0000-0001-7366-077X

IV Enfermeira. Doutora em Enfermagem. Universidade do Estado de Santa Catarina. Chapecó, Santa Catarina, Brasil. E-mail: denise9704@gmail.com; ORCID: https://orcid.org/0000-0003-4754-8439

v Enfermeira. Doutora em Enfermagem. Universidade do Estado de Santa Catarina. Chapecó, Santa Catarina, Brasil. E-mail: elisangela.zanatta@udesc.br; ORCID: https://orcid.org/0000-0002-7426-6472
} 
Vivências e significados da Consulta do Enfermeiro em puericultura: análise à luz de... $\mid 2$

Descritores: Processo de enfermagem; Cuidado da criança; Atenção primária à saúde; Teoria de enfermagem; Enfermeiro

Abstract: Aims: to analyze the meanings attributed to the Nurse Consultation in childcare in Primary Health Care in the light of the Theory of Wanda Horta and to know the experiences of these professionals regarding its operation. Method: action research with 15 nurses working in Primary Health Care. Data collected through semistructured interviews, organized, considering content analysis and interpreted in the light of Theory. Results: three categories emerged: Past and current history of the child and his family; Steps for the implementation of systematic care and Difficulties to carry out the Consultation of Nurses in childcare in Primary Health Care. Conclusion: in their experiences, nurses report difficulties that culminate in the fragmentation of the consultation, however, they mean it as an opportunity to get to know the child and family in their entirety. Systematic operationalization of the Consultation in childcare provides professional empowerment, qualification of assistance and strengthening of the profession as a science of care.

Descriptors: Nursing process; Childcare, Primary health care; Nursing theory; Nurse

Resumén: Objetivos: analizar los significados atribuidos a la Consulta de Enfermeras en puericultura en Atención Primaria de Salud a la luz de la Teoría de Wanda Horta y conocer las experiencias de estos profesionales con respecto a su funcionamiento. Método: investigación de acción con 15 enfermeras que trabajan en Atención Primaria de Salud. Datos recopilados a través de entrevistas semiestructuradas, organizadas, considerando análisis de contenido e interpretadas a la luz de la teoría. Resultados: se revelaron tres categorías: historia pasada y actual del niño y su familia; Pasos para la implementación de la atención sistemática y Dificultades para realizar la Consulta de Enfermeras en la atención infantil en Atención Primaria de Salud. Conclusión: en sus experiencias, las enfermeras reportan dificultades que culminan en la fragmentación de la Consulta, sin embargo, significan una oportunidad para conocer al niño y familia en su totalidad. La operacionalización sistemática de la Consulta en el cuidado de niños proporciona el empoderamiento profesional, la calificación de la asistencia y el fortalecimiento de la profesión como ciencia de la atención.

Descriptores: Proceso de enfermería, Cuidado del niño, Atención primaria de salud; Teoria de enfermería; Enfermero

\section{Introdução}

A Atenção Primária à Saúde (APS), atualmente regida pela Política Nacional da Atenção Básica (PNAB), elenca, dentre outras possibilidades, a Equipe de Saúde da Família (EqSF) como estratégia para sua expansão, qualificação e consolidação. O enfermeiro integra a EqSF e desenvolve atividades que visam qualificar o atendimento às pessoas e coletividades na APS. Dentre essas atividades destaca-se a Consulta do Enfermeiro (CE). ${ }^{1-2}$

A CE é regulamentada pelo Conselho Federal de Enfermagem (COFEN) por meio da Resolução no 358 de 2009, sendo considerada correspondente ao Processo de Enfermagem (PE), 
quando realizada em instituições prestadoras de serviços ambulatoriais, domicílios, escolas, dentre outros. Além disso, sua operacionalização deve ser guiada por cinco etapas interconectadas: Histórico de Enfermagem; Diagnósticos de Enfermagem; Planejamento; Implementação e Avaliação de Enfermagem, as quais devem estar ancoradas por um suporte teórico que oriente o enfermeiro na implementação de cada etapa. ${ }^{3-4}$

Nesse contexto, a dinamicidade do processo que envolve a CE proporciona um olhar voltado ao ser humano e suas necessidades humanas básicas. Dessa forma, fornece ações a serem realizadas de acordo com as necessidades do indivíduo, família e comunidade de maneira sistematizada e orientada por modelos teóricos que auxiliam o enfermeiro na compreensão da prática. $^{5}$

A operacionalização da CE na APS, voltada à criança, tem como objetivo primordial acompanhar seu crescimento físico e desenvolvimento psíquico e social. O foco principal é a identificação precoce de agravos que possam interferir no processo saudável, considerando a criança inserida em seu contexto familiar, cultural e comunitário, bem como orientações de cuidados necessários. ${ }^{6}$ Para a realização da CE em puericultura é recomendado um calendário mínimo de sete consultas no primeiro ano de vida, duas no segundo ano e, a partir do terceiro ano de vida, consultas anuais, próximas ao mês do aniversário. Sendo que aquelas que necessitam de maior atenção devem ser acompanhadas com maior frequência., ${ }^{1,7}$

Embora a CE seja uma atividade regulamentada e discutida na contemporaneidade, observa-se que os enfermeiros pouco a incorporaram no seu cotidiano como algo inerente à profissão, da maneira como é preconizada e com a resolutividade desejada, especialmente, quando voltada à criança. Estudo ${ }^{8}$ realizado na Austrália discute que os enfermeiros relatam dificuldades em atender as demandas e necessidades infantis, pois sentem-se despreparados. Para isso, precisam de apoio e formação constante para manterem-se atualizados e habilitados para esse atendimento. Outra pesquisa ${ }^{2}$ desenvolvida na Paraíba demonstra que as dimensões do 
Vivências e significados da Consulta do Enfermeiro em puericultura: análise à luz de... 4

cuidado realizadas em maior proporção pelos enfermeiros na APS foram a avaliação da imunização e as suplementações de ferro e vitamina A; a anamnese, o acolhimento, o exame físico/desenvolvimento neuropsicomotor e a educação em saúde foram as menos efetivadas pelos enfermeiros. ${ }^{2}$

A Consulta em puericultura por enfermeiros privilegia aspectos como presença de intercorrências e alimentação da criança, avalia o crescimento e a imunização. A avaliação do desenvolvimento e orientações próprias a cada faixa etária são incompletas. ${ }^{9}$ Outros estudos ainda estão focados em aspectos e condições específicas como crescimento e desenvolvimento ${ }^{10}$ e desmame precoce,${ }^{11}$ mostrando que essa é uma prática adotada pelo enfermeiro na APS e que precisa ser discutida, abrangendo a Consulta em puericultura na qual a criança é avaliada em sua totalidade e periodicamente.

Considerando o exposto e face a importância do cuidado integral a criança que acontece no nível primário de atenção à saúde, é fundamental refletir acerca das vivências e significados desses profissionais para que se possa colher informações que darão subsídios para a reflexão dessa prática e, com isso, instigar movimentos de mudança no cenário vivenciado. Nesse sentido, pergunta-se quais os significados atribuídos à Consulta do Enfermeiro em puericultura por enfermeiros da APS? Quais as vivências dos enfermeiros acerca da sua operacionalização?

Esse artigo tem como objetivos analisar os significados atribuídos à Consulta do Enfermeiro em puericultura na Atenção Primária à Saúde à luz da Teoria de Wanda Horta e conhecer as vivências desses profissionais acerca da sua operacionalização.

\section{Método}

Trata-se de uma pesquisa qualitativa do tipo pesquisa-ação, desenvolvida em seis etapas adaptadas, ${ }^{12}$ sendo: fase exploratória, diagnóstico de situação, coleta de dados, seminários 
integradores, planejamento de qualificação dos profissionais enfermeiros e publicização. Neste artigo serão descritos os resultados oriundos da etapa da coleta de dados.

Pesquisa realizada com 15 enfermeiros que atuam na APS de um município do Meio Oeste de Santa Catarina. Realizou-se o levantamento dos profissionais registrados no Cadastro Nacional de Estabelecimentos de Saúde no mês de abril de 2018, o que totalizou 19 enfermeiros. Aplicou-se os critérios de inclusão: ser enfermeiro e atuar no cuidado à criança na APS. Foram excluídos enfermeiros que estavam em afastamento por motivo de licença e que atuavam no cargo há menos de seis meses, resultando na exclusão de quatro profissionais.

A coleta de dados ocorreu entre os meses de maio e junho de 2018, por meio de entrevistas individuais, conduzidas a partir de um roteiro semiestruturado, ${ }^{13}$ com questões abertas. Para preservar o anonimato os enfermeiros foram identificados pela letra $\mathrm{E}$ (enfermeiro), seguido por um número ordinal, atribuído conforme a ordem da entrevista. Os participantes assinaram o Termo de Consentimento Livre e Esclarecido.

Os dados foram organizados seguindo as etapas da análise de conteúdo ${ }^{14} \mathrm{e}$ interpretados à luz da Teoria de Wanda Horta. ${ }^{5}$ As três etapas que compõem a análise são: pré-análise; exploração e tratamento dos resultados e; inferência e interpretação. ${ }^{14}$ A etapa da pré-análise ocorreu durante toda a coleta de dados, realizou-se a transcrição das entrevistas, organização e a leitura geral do material produzido. Na fase de exploração e tratamento dos resultados, foram realizadas leituras em profundidade desse material, visando identificar categorias e subcategorias. Na última fase, da inferência e interpretação dos resultados, foi possível a aproximação dos resultados extraídos dos depoimentos e a discussão com a literatura científica e com a Teoria de Wanda Horta, ${ }^{5}$ visando dar significado e validade aos dados brutos, resultando em categorias.

A pesquisa seguiu as normativas da Resolução no 466 de 2012 do Conselho Nacional de Saúde para pesquisa, envolvendo seres humanos e os princípios da bioética, autonomia, não 
Vivências e significados da Consulta do Enfermeiro em puericultura: análise à luz de... 6

maleficência, beneficência, justiça e equidade, sendo aprovada pelo Comitê de Ética local sob Parecer nํ. 2.630.923 em 02 de maio de 2018.

\section{Resultados}

O tratamento dos dados deu origem a três categorias: História pregressa e atual da criança e sua família; Etapas para a implementação do cuidado sistematizado e Dificuldades para realizar a Consulta do Enfermeiro em puericultura na Atenção Primária à Saúde, as quais permitiram a compreensão do significado da CE em puericultura para o enfermeiro e a identificação da sua operacionalização na APS.

\section{História pregressa e atual da criança e sua família}

Para os enfermeiros, a CE em puericultura é uma atividade que permite conhecer a história pregressa e atual da criança e sua família e identificar suas principais necessidades. Esse reconhecimento ocorre, especialmente, na etapa de coleta de dados.

É o processo onde eu vou conversar, investigar o que ela [referindo-se à criança] está precisando. (E1)

É um momento em que a gente disponibiliza uma atenção especial, vai ouvir, examinar, fazer o histórico da criança através da Consulta de Enfermagem. (E6)

Colher informações junto à família da criança tentando levantar algumas situações que você não vê nos sintomas, é uma conversa. (E9)

No primeiro contato, a gente faz o acolhimento, identifica a necessidade da criança. (E14)

A primeira etapa da consulta possibilita ao enfermeiro conhecer a criança e sua família. Favorece a avaliação da criança por meio do exame físico, utilizando-se para isso dos métodos propedêuticos de inspeção, percussão, palpação e ausculta. Para os enfermeiros, esse é o 
momento de realizar a escuta qualificada, o que requer competência, habilidade e conhecimento com vistas a desenvolver a $\mathrm{CE}$ em puericultura na sua integralidade.

Entender a criança, avaliar dos pés à cabeça, avaliar a situação como um todo. (E3)

É aquilo que o enfermeiro tem a capacidade, as habilidades para estar fazendo de forma integrada, tentando ao máximo abranger toda a história da criança. (E4)

Ver o indivíduo como um todo, fazer toda a parte do histórico, toda a parte de uma introdução, exame físico, é ouvir a necessidade da criança. (E7)

\section{Etapas para a implementação do cuidado sistematizado}

A CE em puericultura, realizada pelos enfermeiros, tem seu significado atribuído à realização de uma sequência de etapas sistematizadas que viabilizam o cuidado integral à criança.

Levantar problemas que, às vezes, acaba descobrindo na CE em puericultura, por isso, tem a sistematização da CE, onde tem os passos que agente deve seguir. (E9)

[...] procuro fazer a anamnese da criança, vendo qual é o problema, realizar o exame físico, pegar o histórico, para daí, então, fazer um diagnóstico de enfermagem, e dar o devido encaminhamento. (E10)

Outros enfermeiros significam a CE em puericultura como um processo de investigação. Observa-se, contudo que possuem dificuldade em diferenciar os significados entre Sistematização da Assistência de Enfermagem (SAE), PE e CE, condição que pode enredar o entendimento da metodologia na prática assistencial.

É um roteiro que o enfermeiro deve seguir para fazer um atendimento à criança, desde a anamnese, a entrevista, levantamento de problemas até chegar numa prescrição. (E5) 
Vivências e significados da Consulta do Enfermeiro em puericultura: análise à luz de... $\mid 8$

É o desenvolvimento do PE, com todas suas etapas desde a avaliação, a anamnese, o exame físico, o diagnóstico, as prescrições e avaliação, então, a continuidade do planejamento. (E13)

É o momento onde você tem que aplicar a SAE, aonde faz parte todo o processo da SAE, o exame físico, a entrevista, anamnese, o planejamento, todos os passos da sistematização da assistência. (E15)

Embora os enfermeiros identifiquem as etapas da CE em puericultura e a importância de realizá-las no contexto do processo de trabalho de forma sistematizada, emergem dos depoimentos dos enfermeiros E2 e E3, relatos de dificuldades para operacionalizá-la em todas as suas etapas, de modo sistemático. O que pode significar que existe uma fragmentação no cuidado prestado à criança, dificultando o atendimento integral.

CE em puericultura é o que engloba o todo, desde a anamnese, exame físico, avaliação do contexto social, não só de saúde, a implementação, mas a utilização é o que a gente não faz e que faz parte da SAE. (E2)

A CE em puericultura deve ser entendida bem mais que do que na verdade eu faço no meu dia a dia aqui na unidade de saúde [...] então, o que entendo que a CE deveria ser é entender a criança, fazer a avaliação, identificar os fatores, fazer os diagnósticos de enfermagem e fazer um plano de assistência. (E3)

\section{Dificuldades para realizar a Consulta do Enfermeiro em puericultura na Atenção Primária à}

\section{Saúde}

Essa categoria apresenta os obstáculos para a operacionalização da CE em puericultura na vivência dos enfermeiros. Ao serem questionados quanto à realização da CE à criança, dos 15 enfermeiros, nove responderam que não a realizam. Quando questionados sobre os motivos, as respostas relacionaram-se com a identificação de obstáculos, mais especificamente da falta de instrumentos e rotinas, que são pontuados na sequência. 
[...] não tem um cronograma ou um roteiro de como fazer essas consultas, a puericultura é uma das que a gente ainda não faz. (E1)

[...] a gente não tem um protocolo desse atendimento [referindo-se a CE em puericultura], eu vejo que a gente acaba perdendo como enfermeiro, no momento que se cria um protocolo fica mais fácil de você conseguir fazer com que esse programa funcione. (E9)

Os enfermeiros fazem menção a falta de rotina implementada na UBS para a realização da CE em puericultura. Além disso, relatam que há rotatividade dos profissionais, dificultando a criação de vínculo entre a equipe, famílias e comunidade, resultando na pouca confiança no enfermeiro que realiza a consulta. Foi destacado ainda pelos enfermeiros a falta de incentivo por parte da gestão local às atividades de Educação Permanente em Saúde (EPS), bem como, o pouco interesse por parte dos próprios profissionais em buscar por qualificações.

No nosso município, não está inserido, como rotina à CE para a criança, então, por isso, não é realizado. (E1)

[...] eu tentei desenvolver a puericultura nas outras unidades, mas quando estava desenvolvendo, me trocavam de unidade e acabei desanimando. [...] tem todo um trabalho para você trazer as crianças para unidade, chamar através das Agentes de Saúde, aí quando começa a se desenvolver a rotina, me trocam de unidade, por isso, hoje não estou fazendo. (E11)

[...] diante de vários aspectos tarefeiros que nós temos durante o dia, no nosso mês, na nossa semana, eu acho que nos é pouco incentivado a CE em puericultura dentro da Atenção Básica no município, nós não temos ferramentas para isso. (E15)

[...] faltam ferramentas, capacitações, atualizações e a vontade do profissional também. (E15) 
Vivências e significados da Consulta do Enfermeiro em puericultura: análise à luz de... $\mid 10$

Emerge nos relatos dos enfermeiros dificuldades no sentido da organização do processo de trabalho interprofissional centrado na criança, pois a presença do médico pediatra em algumas UBS é entendida por eles como causa da baixa adesão à CE em puericultura.

[...] as mães, por já terem esse costume, porque ela está aqui há bastante tempo [referindo-se ao médico pediatra], não tem confiança e segurança de consultar com o enfermeiro. (E4)

Como tem o pediatra na unidade, quatro dias na semana, normalmente vai direto para o pediatra [referindo-se à consulta da criança]. (E10)

Além dessas dificuldades, os enfermeiros também relatam como obstáculos, a falta do preparo e conhecimento para a realização da CE em puericultura.

Não fazia por não saber como conduzir, muita dificuldade em lidar com criança [...]. A puericultura é bem falha porque eu não tinha o conhecimento. (E2)

[...] não me sinto preparada, não tive uma preparação para isso, embora a gente tenha o amparo bibliográfico, eu não tive uma capacitação, um treinamento ou o ponta pé inicial para isso, então eu não me sinto preparada. (E14)

Para fazer um exame físico completo na criança eu teria dificuldade, uma ausculta pulmonar, uma ausculta cardíaca, isso faz parte do exame físico, dentro da CE em puericultura. Então, eu acho que também falta conhecimento. (E15)

Além dos obstáculos destacados, alguns enfatizam que existem dificuldades institucionais relacionadas à estrutura física, material e escassez de recursos humanos.

A outra equipe ficou sem enfermeiro, então, eu fiquei responsável pelas duas equipes, acabei não fazendo [referindo-se a CE em puericultura], não tinha horário na agenda para fazer. (E3)

Acho que falta mais estrutura física, mais espaço. Faltam equipamentos necessários para realizar uma consulta de criança, como uma maca adequada, colchonete, balança. (E7) 


\section{Discussão}

A CE realizada de forma sistematizada possibilita produzir mudanças individuais e coletivas com vistas a desenvolver práticas educativas e de cuidado voltadas à prevenção de doenças, promoção e recuperação da saúde. No cenário da APS, em que o ser humano é contemplado nas diferentes etapas do ciclo vital e, nas diversas dimensões de saúde e doença, visualiza-se a CE como estratégia para a realização dessas ações, especialmente quando voltadas à criança que se encontra em uma fase com mais vulnerabilidades e riscos. Nesse sentido, intervenções precoces e periódicas podem gerar impactos positivos no seu processo de crescimento e desenvolvimento, corroborando para que sejam adultos saudáveis. ${ }^{2,15-16}$

Os enfermeiros compreendem a primeira etapa da CE em puericultura, o Histórico de Enfermagem, como um momento importante para estabelecer uma relação com a criança e família e a oportunidade para identificar suas necessidades. Essa etapa possibilita ao enfermeiro realizar uma avaliação integral da criança, utilizando-se de tecnologias como escuta qualificada e instrumentos para a avaliação do estado físico, social e emocional, e a partir disso, realizar julgamentos, traçar diagnósticos e elaborar o plano de cuidados.

O entendimento dos enfermeiros está alinhado às ideias da Teoria, ${ }^{5}$ em que a primeira etapa da CE, é o momento ideal para realizar o levantamento de dados e informações acerca do indivíduo, por intermédio deste, da sua família, do seu prontuário e complementado pelas observações do enfermeiro que o realiza e pelo exame físico, os quais servirão de base para a construção das demais etapas do cuidado. Similarmente é o que dispõe a legislação que trata sobre a CE, em que essa etapa auxiliará o enfermeiro na identificação de problemas e potencialidades por meio do raciocínio clínico. ${ }^{3}$

Esse resultado também condiz com estudo ${ }^{17}$ que identificou, na perspectiva materna, a existência do vínculo entre os enfermeiros e mães de crianças menores de dois anos de idade, 
Vivências e significados da Consulta do Enfermeiro em puericultura: análise à luz de... | 12

corroborado pela CE em puericultura na APS, afirmando que o vínculo favorece a procura por esse serviço. Assim, a escuta qualificada, compreendida a partir do estabelecimento de relações interpessoais, que se inicia no acolhimento da criança e família e a construção de laços de confiança e vínculo com o profissional, são importantes no estabelecimento de parcerias colaborativas que podem garantir a resolução de problemas. ${ }^{2}$

Ao encontro do presente estudo, em que os enfermeiros reconhecem a primeira etapa da CE em puericultura como importante para a avaliação infantil integral, estudo ${ }^{18}$ revelou que os enfermeiros identificaram na CE instrumento para o cuidado integral à criança, percebendo-a ainda como facilitadora das relações entre família e equipe de saúde. Nesse sentido, a Teoria ${ }^{5}$ demonstra a importância da totalidade do ser humano, um ser indivisível, que precisa ser entendido a partir de um olhar holístico voltado às suas necessidades. Um ser que possui necessidades psicobiológicas, psicossociais, psicoespirituais, intimamente interconectadas e a enfermagem como reconhecedora do ser pertencente a uma família e comunidade. ${ }^{5}$

$\mathrm{Na}$ presente pesquisa, os enfermeiros expressam ainda, a operacionalização da CE considerando as etapas de acordo com a Resolução, ${ }^{3}$ o que se assemelha a proposta da Teoria ${ }^{5}$ de que o PE ocorre em etapas que se inter-relacionam dinamicamente e proporcionam eficiência e resolutividade por meio do planejamento das ações. Corroborando essa proposta, a Resolução COFEN no 358 de 2009, ${ }^{3}$ organiza as etapas sucessivas ao Histórico de Enfermagem em: Diagnóstico de Enfermagem (DE); Planejamento; Implementação e a Avaliação de Enfermagem. Assim, é importante conhecer e ressaltar a necessidade da realização da CE em puericultura de forma sistematizada, pois do contrário, pode-se fragilizar a assistência prestada à criança com consequente perda da confiança do cuidado implementado pelo enfermeiro.

Nesse sentido, acredita-se que a implantação e implementação da CE possa auxiliar na organização dos processos de trabalho. Contudo, observa-se que somente a legislação que trata desse assunto não é suficiente para assegurar que uma rotina seja implementada, se faz 
necessário movimentos em diferentes áreas para que a CE em puericultura se desenvolva como rotina nos serviços.

Situação que talvez dificulte a consolidação da CE em puericultura, no cenário em estudo, é a confusão que os enfermeiros fazem com os termos SAE, PE e CE. Os resultados corroboram com pesquisa ${ }^{19}$ que revela dificuldades no uso das nomenclaturas e conceituação dos termos pelos enfermeiros, justificando que a maioria dos participantes pouco ou nada aprendeu sobre a metodologia na sua formação, dificultando, assim, a compreensão.

A presente pesquisa revelou, também, a fragmentação na realização da CE em puericultura. Os enfermeiros dizem não conseguir implementar todas as etapas de forma sistematizada, o que dificulta o cuidado infantil integral e põe em dúvida a cientificidade do processo. Estudos ${ }^{2,4}$ mostram resultados semelhantes e abordam o pouco conhecimento dos profissionais acerca da metodologia, fragilidade nos registros e a realização das etapas de forma parcial. Além disso, revelam a falta de embasamento teórico para sustentar as etapas da CE, dificultando o raciocínio clínico, estabelecimento de metas e avaliação das ações fundamentadas por uma Teoria de Enfermagem.

Desse modo, faz-se necessário movimentos de EPS para resgatar conceitos e a aplicabilidade da SAE, PE e da CE, diminuindo as dificuldades de aprendizado e de operacionalização da metodologia. A integração entre enfermeiros, equipe de saúde, gestores locais e órgãos fiscalizadores é necessária para promover o amplo debate e o apoio para a realização dessas atividades. O diálogo e a reflexão da realidade local são essenciais para a transformação desta realidade. ${ }^{2,4,19}$

Outro destaque do presente estudo, se relaciona aos fatores que interferem na realização da CE em puericultura. Apesar do entendimento dos enfermeiros quanto à importância da sua adoção, os mesmos relatam situações que contribuem para que não seja desenvolvida no dia a dia, como dificuldades organizacionais, institucionais e pessoais. Esses achados são reforçados 
Vivências e significados da Consulta do Enfermeiro em puericultura: análise à luz de... $\mid 14$

por estudos ${ }^{1,6,20}$ que também identificaram fatores contribuintes para a limitação na realização da CE. Dentre as quais, cita-se a falta de capacitações, resistência dos pais para consultas com o enfermeiro, burocracia, espaço físico inadequado e o protagonismo da figura médica, especialmente do pediatra.

Nesse sentido, quando os enfermeiros relatam como obstáculos para a operacionalização da CE em puericultura a falta de um documento guia, de instrumentos e rotina institucional, os protocolos assistenciais se apresentam como uma possibilidade no enfrentando aos fatores que dificultam a sua realização. O protocolo assistencial pode contribuir para a organização dos processos e rotinas de trabalho e para a sistematização da CE em puericultura, facilitando o registro e organização dos dados. Assim, criar um instrumento a partir da realidade vivenciada agrega valor para sua efetividade. Além disso, auxilia no acompanhamento do crescimento e desenvolvimento da criança por facilitar a observação dos dados obtidos, permitindo o cuidado holístico, auxiliando nas orientações à família de forma padronizada com base em evidências. ${ }^{6,15}$

Em relação à rotatividade dos profissionais nas EqSF, obstáculo apontado pelos participantes dessa pesquisa em justificativa a não realização da CE em puericultura, estudo ${ }^{21}$ verificou que a média de atuação dos enfermeiros nas equipes foi de quatro anos. Contudo, a variação por Estado, quando avaliada separadamente, revelam profissionais que atuam há menos de um ano. A rotatividade contribui para a sobrecarga de trabalho, demanda tempo e custos para treinamento de novos profissionais e, sobretudo, fragiliza os processos de trabalho. O estabelecimento de vínculo entre profissionais, equipe e comunidade é outro importante instrumento de trabalho comprometido., ${ }^{62}$

Os enfermeiros dessa pesquisa destacam ainda, dificuldades na organização de processos de trabalho interprofissionais, uma vez que para eles, a presença do médico pediatra na UBS é causa de baixa adesão à CE em puericultura. A despeito dessa premissa, estudo ${ }^{1}$ corrobora essa percepção de 
que o médico é o profissional competente para a realização da consulta em puericultura, especialmente o pediatra, retratando uma visão medicocêntrico da assistência à saúde.

Entretanto, as ações preconizadas na APS sugerem intercalar consultas de puericultura entre médico e enfermeiro, pensamento esse que se assemelha a óptica da Teoria, ${ }^{5}$ em que a enfermagem integra a equipe de saúde, auxiliando o ser humano em suas necessidades humanas básicas, sendo que conta, para isto, com o apoio de outros profissionais. ${ }^{5}$ A alternância dos profissionais nas consultas de puericultura visa complementar o trabalho em equipe, visto que cada um tem o um olhar diferenciado para o cuidado à criança, buscando, assim, o compartilhamento de saberes e práticas e o aperfeiçoamento do cuidado. ${ }^{6-7}$ Além da relação interprofissional entre médico e enfermeiro, há a necessidade de interlocução do enfermeiro com outros profissionais. Recomenda-se ainda, consultas odontológicas periódicas e o encaminhamento para os profissionais que compõem o Núcleo de Apoio à Saúde da Família (NASF) quando necessário, fortalecendo a atenção à saúde abrangente e integral.7,18,22

Em relação aos processos de trabalho foi identificado, no presente estudo, como obstáculo para a realização da CE em puericultura, questões relacionadas à organização da rotina e falta de incentivo por parte da gestão local para atividades de EPS. Em relação a isso, autores $^{6,22}$ sinalizam que a má organização das tarefas afeta negativamente a prática da puericultura. Para que mudanças ocorram, é necessário o envolvimento da equipe e, sobretudo da gestão local para que sejam desenvolvidas atividades de capacitação e formação dos profissionais. ${ }^{23}$ Há a necessidade de planejamento, elaboração e execução de ações, programas e protocolos que instituam fluxos e processos por meio da elaboração participativa dos atores envolvidos, bem como dos usuários, promovendo a pactuação das ações com base nas necessidades locais. ${ }^{6,20,23} \mathrm{O}$ PE caracteriza-se como um instrumento metodológico de trabalho, entretanto para que seja implementado é necessário que os enfermeiros reconheçam a importância dessa tecnologia na APS, sobretudo na puericultura. ${ }^{6,23}$ 
Vivências e significados da Consulta do Enfermeiro em puericultura: análise à luz de... | 16

Observou-se ainda por parte dos enfermeiros, certo comodismo em buscar por qualificações, situações que dificultam a operacionalização da CE em puericultura na APS, reforçada por obstáculos relacionados à estrutura física, material e recursos humanos. Em relação às limitações pessoais dos enfermeiros para a operacionalização da CE em puericultura, estudos $^{2,6}$ apresentam resultados semelhantes ao revelarem que enfermeiros encontram dificuldades na realização do exame físico, avaliação do crescimento e desenvolvimento infantil e registro dos dados, reflexo, talvez do pouco embasamento teórico desses profissionais. Outras fragilidades giram em torno de limitações estruturais, sobrecarga de trabalho, excesso de atividades burocráticas, grande demanda de pacientes e postura passiva dos enfermeiros.

Assim, atividades de EPS precisam ser constantes na vida profissional do enfermeiro, pois aprimoram a assistência, mantendo-o sempre atualizado e capacitado. Proporcionam ainda, maior confiança e habilidade no desenvolvimento das atividades que exigem tanto o raciocínio clínico como a desenvoltura técnica o que contribui para que as famílias se sintam mais seguras, permitindo o estreitamento dos laços de confiança e vínculo. ${ }^{6,16}$ Desse modo, é imprescindível que o profissional busque por conhecimentos, pois o campo de atuação é repleto de dinamismo, sobretudo na puericultura, o que pode significar oportunidades para novas experiências e aprendizados, tornando o cuidado cada vez mais qualificado. ${ }^{6,23-24}$

Em relação aos gestores locais, é necessário assumir sua responsabilidade na continuidade da formação e qualificação dos profissionais, concretizando com isso, os pressupostos da Política Nacional de Educação Permanente em Saúde (PNEPS), incorporando o ensino e o aprendizado no cotidiano da APS, visto que a educação permanente é uma estratégia para consolidação de mudanças na prática assistencial. A problematização da realidade contribui para que os profissionais se tornem reflexivos quanto a sua prática e construtores de conhecimentos e soluções, além disso, centra-se nos processos de trabalho, pois não se limita a categorias profissionais, e sim a equipe de saúde. ${ }^{4,24}$ 
Algumas situações podem ser consideradas de difícil resolução, como os recursos humanos e infraestrutura, pois dependem de investimentos governamentais. É imprescindível que a gestão local trabalhe em conjunto com a assistência, pois cabe a esses gestores dar viabilidade ao processo de implementação de uma metodologia assistencial com base científica por meio da organização de sua estrutura. Os protocolos assistenciais, novamente, se apresentam como um importante instrumento, possibilitando durante sua construção coletiva, a pactuação de condutas baseadas na realidade local, que sustentem a operacionalização da CE em puericultura, prevendo e provendo a estrutura, materiais e a dinâmica necessária para a atividade..$^{4,6,15}$

Desse modo, apesar das dificuldades destacadas nesse estudo é possível identificar que o enfermeiro vem conquistando seu espaço nas EqSF e na comunidade, pelo papel que desempenha. A responsabilidade do enfermeiro com o cuidado à criança se reflete no estabelecimento de vínculos com ela e sua família e da autonomia profissional que se fortalece por meio da CE em puericultura, tecnologia que permite maior organização e direcionamento das ações no processo do cuidado permeado por conhecimentos científicos, os quais possibilitam atingir resultados benéficos no cuidado à criança na APS..$^{1,6,18-19}$

Esse estudo possui como limitação o cenário de investigação, pois se optou em ouvir os enfermeiros de apenas um município. Faz-se necessário ampliá-lo, buscando compreender o significado da CE em puericultura para enfermeiros de outros municípios, bem como à luz da equipe, gestão e usuários, ampliando, assim, a compreensão sobre a CE em puericultura e as possibilidades para torná-la resolutiva.

\section{Conclusão}

Os significados atribuídos pelos enfermeiros sobre a CE em puericultura estão relacionados à oportunidade para conhecer a criança e a família na sua integralidade, pautada 
Vivências e significados da Consulta do Enfermeiro em puericultura: análise à luz de... $\mid 18$

pela escuta qualificada, oportunizando a criação do vínculo e facilitando a orientação para os cuidados. Suas vivências na APS revelam fatores que interferem na operacionalização da CE em puericultura, relacionadas às dificuldades organizacionais, institucionais e pessoais que possuem como consequência o desempenho da consulta de forma fragmentada.

Frente aos obstáculos identificados, a construção de instrumentos padronizados para guiar a CE e os protocolos assistenciais, foram destacados por entenderem que esses ajudam nortear suas ações e lhes proporcionam respaldo legal para a realização da CE em puericultura. Entretanto, é importante que a construção desses instrumentos aconteça de forma coletiva, incluindo profissionais e gestores em espaços de EPS com amplas discussões acerca da SAE, PE e CE, especialmente, em puericultura possibilitando que sua implementação e operacionalização seja viabilizada.

A operacionalização da CE em puericultura na APS proporciona uma assistência qualificada à criança e a sua família, com vistas à integralidade do cuidado. Além disso, contribui para o empoderamento do enfermeiro, possibilitando que esse profissional se sinta capaz e confiante para o desenvolvimento de suas atividades, pois estão pautadas em evidências, resultando na autonomia profissional e fortalecendo a profissão como ciência do cuidado. Salienta-se, ainda, a necessidade em adotar um referencial teórico que oriente as práticas do enfermeiro durante a CE, contribuindo para a compreensão do cuidado proposto. Nesse estudo, a Teoria de Wanda Horta favoreceu a aproximação entre os conceitos teóricos e os significados atribuídos pelos enfermeiros em relação a CE e a inter-relação com o cuidado, possibilitando refletir e organizar suas práticas em conformidade com as necessidades da criança e sua família de forma acolhedora e resolutiva.

\section{Referências}

1. Malaquias TSM, Gaíva MAM, Higarashi IH. Perceptions of the family members of children regarding 
well-child check-ups in the family health care strategy. Rev Gaúch Enferm. 2015;36(1):62-8. doi: 10.1590/1983-1447.2015.01.46907

2. Vieira DS, Santos NCCB, Nascimento JA, Collet N, Toso BRGO, Reichert APS. Nursing practices in child care consultation in the Estratégia Saúde da Família. Texto Contexto Enferm. 2018;27(4):e4890017. doi: 10.1590/0104-07072018004890017

3. Conselho Federal de Enfermagem (COFEN). Resolução no 358 de 2009. Dispõe sobre a Sistematização da Assistência de Enfermagem e a implementação do processo de enfermagem em ambientes públicos ou privados, em que ocorra o cuidado profissional de Enfermagem [Internet]. 2009 [acesso em $2018 \mathrm{dez}$ 10]. Disponível em: http://www.cofen.gov.br/resoluo-cofen-3582009_4384.html

4. Diniz IA, Cavalcante RB, Otoni A, Mata LRF. Perception of primary health care management nurses on the nursing process. Rev Bras Enferm. 2015;68(2):182-9. doi: 10.1590/0034-7167.2015680204i

5. Horta WA. Processo de Enfermagem. São Paulo: EPU; 1979.

6. Góes FGB, Silva MA, Paula GK, Oliveira LPM, Mello NC, Silveira SSD. Nurses' contributions to good practices in child care: an integrative literature review. Rev Bras Enferm. 2018;71(Suppl 6):2808-17. doi: 10.1590/0034-7167-2018-0416

7. Ministério da Saúde (BR), Secretaria de Atenção Básica à Saúde, Departamento de Atenção Básica. Saúde da Criança: crescimento e desenvolvimento. Brasília (DF): Ministério da Saúde; 2012. (Cadernos de Atenção Básica; 33).

8. Walsh A, Barnes M, Mitchell AE. Nursing care of children in general practice settings: roles and responsibilities. J Adv Nurs. 2015;71(11):2585-94. doi: 10.1111/jan.12735

9. Faller TT, Toso BRGO, Viera CS, Baggio MA. A consulta de enfermagem em puericultura na Estratégia Saúde da Família. Rev Varia Scientia [Internet]. 2018 [acesso em 2020 maio 15];4(2):137-47. Disponível em: http://saber.unioeste.br/index.php/variasaude/article/view/19656/13688

10. Gaiva MAM, Monteschio CAC, Moreira MDS, Salge AKM. Child growth and development assessment in nursing consultation. Av Enferm. 2018;36(1):9-21. doi: 10.15446/av.enferm.v36n1.62150

11. Monteschio CAC, Gaíva MAM, Moreira MDS.The nurse faced with early weaning in child nursing consultations. Rev Bras Enferm. 2015;68(5):869-75. doi: 10.1590/0034-7167.2015680515i

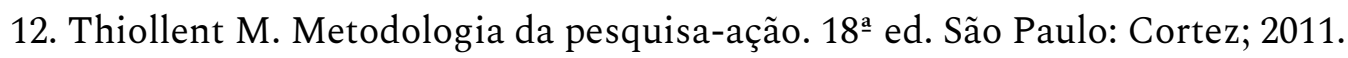

13. Minayo MCS. Pesquisa social: teoria, método e criatividade. Petrópolis: Vozes; 2016.

14. Bardin L. Análise de conteúdo. Ed. rev. e ampl. São Paulo: Edições 70; 2016.

15. Almeida ER, Moutinho CB, Carvalho SAS, Araújo MRN. Report about the construction of a nursing 
Vivências e significados da Consulta do Enfermeiro em puericultura: análise à luz de... $\mid 20$

protocol in childcare in primary care. Rev Enferm UFPE On Line [Internet]. 2016 [cited 2018 Dec 10];10(2):683-91. Available from: https://periodicos.ufpe.br/revistas/revistaenfermagem/article/view/11006

16. Oberklaid F, Baird G, Blair M, Melhuish E, Hall D. Children's health and development: approaches to early identification and intervention. Arch Dis Child. 2013;98(12):1008-11. doi: 10.1136/archdischild-2013304091

17. Reichert APS, Rodrigues PF, Cruz TMAV, Dias TKC, Tacla MTGM, Collet N. Mothers' perception about the relationship with nurses in the child consultation. Rev Enferm UFPE On Line [Internet]. 2017 [cited $2020 \quad$ May 15];11(2):483-90. Available from: https://periodicos.ufpe.br/revistas/revistaenfermagem/article/view/11965

18. Furtado MCC, Mello DF, Pina JC, Vicente JB, Lima PR, Rezende VP. Nurses' actions and articulations in childcare in primary health care. Texto Contexto Enferm. 2018;27(1):1-11. doi: 10.1590/0104-07072018000930016

19. Krauzer IM, Adamy EK, Ascari RA, Ferraz L, Trindade LL, Neiss M. Nursing care systematization in primary care: what do the nurses say? Cienc Enferm (En Línea). 2015;21(2):31-38. doi: 10.4067/S071795532015000200004

20. Hagos F, Alemseged F, Balcha F, Berhe S, Aregay A. Application of nursing process and its affecting factors among nurses working in mekelle zone Hospitals, Northern Ethiopia. Nurs Res Pract. 2014; 2014:675212. doi: $10.1155 / 2014 / 675212$

21. Gavalote HS, Zandonade E, Garcia ACP, Freitas PSS, Seidl H, Contarato PC, et al. The nurse's work in primary health care. Esc Anna Nery Rev Enferm. 2016;20(1):90-8. doi: 10.5935/1414-8145.20160013

22. Damasceno SS, Nóbrega VM, Coutinho SED, Reichert APDS, Toso BRGDO, Collet N. Children's health in Brazil: orienting basic network to Primary Health Care. Ciênc Saúde Colet. 2016;21(9):2961-73. doi: 10.1590/1413-81232015219.25002015

23. Adamy EK, Zocche DAA, Almeida MA. Contribuição do processo de enfermagem para construção identitária dos profissionais de Enfermagem. Rev Gaúch Enferm. 2020;41(Spec No):e20190143. doi: 10.1590/1983-1447.2020.20190143

24. Viana DMS, Nogueira CA, Araújo RS, Vieira RM, Rennó HMS, Oliveira VC. A educação permanente em saúde na perspectiva do enfermeiro na Estratégia Saúde da Família. Rev Enferm Cent Oeste Min [Internet]. 2015 [acesso em 2018 dez 10];5(2):1658-668. Disponível em: http://www.seer.ufsj.edu.br/index.php/recom/article/view/470 
Fomento: Edital Coordenação de Aperfeiçoamento de Pessoal de Nível Superior (CAPES) / Conselho Federal de Enfermagem (COFEN) no 27/2016.

\section{Autor correspondente}

Cheila Karei Siega

E-mail: cheilasiega@gmail.com

Endereço: Universidade do Estado de Santa Catarina - Rua 7 de Setembro, 91D, Chapecó/SC,

CEP: 89806-152

\section{Contribuições de autoria:}

\section{1 - Cheila Karei Siega}

Concepção do estudo; análise e interpretação dos dados; revisão final com participação crítica e intelectual no manuscrito.

\section{2 - Edlamar Kátia Adamy}

Concepção do estudo; análise e interpretação dos dados; revisão final com participação crítica e intelectual no manuscrito.

\section{3 - Rosana Beatriz Gonçalves de Oliveira Toso}

Revisão final com participação crítica e intelectual no manuscrito.

\section{4 - Denise Antunes de Azambuja Zocche}

Revisão final com participação crítica e intelectual no manuscrito.

\section{5 - Elisangela Argenta Zanatta}

Concepção do estudo; análise e interpretação dos dados; revisão final com participação crítica e intelectual no manuscrito.

\section{Como citar este artigo}

Siega CK, Adamy EK, Toso BRGO, Zocche DAZ, Zanatta EA. Vivências e significados da Consulta do Enfermeiro em puericultura: análise à luz de Wanda Horta. Rev. Enferm. UFSM. 2020 [Acesso em: Anos Mês Dia]; vol.10 e65: 121. DOI:https://doi.org/10.5902/2179769241597 